\title{
Epidemiological study of an outbreak of infection with Staphylococcus aureus resistant to lincosamides and streptogramin $A$ in a French hospital
}

\author{
C. ARPIN, I. LAGRANGE, J. P. GACHIE*, C. BEBEAR ${ }^{\dagger}$ and C. QUENTIN \\ Laboratoire de Microbiologie, Université de Bordeaux II, 146 rue Léo Saignat, *Laboratoire d'Hygiène \\ Hospitalière and ${ }^{\dagger}$ Laboratoire de Bactériologie, Hôpital Pellegrin, Place Amélie Raba Léon, 33076 Bordeaux \\ Cedex, France
}

\begin{abstract}
A significant increase in the incidence of isolates of methicillin-resistant Staphylococcus aureus (MRSA), that were also resistant to lincosamides and streptogramin $A\left(\mathbf{L S}_{A^{-}}\right.$ MRSA), was observed in a French university hospital. Twenty-seven isolates from the outbreak were characterised, including 17 isolates from a plastic surgery ward and six control strains of MRSA. The strains were examined by antibiotyping and biotyping, and by three molecular methods: plasmid analysis, ribotyping and insertion sequence (IS) typing with IS256 sequence as a probe. Antibiotyping (five antibiotypes) was discriminatory because of the uncommon resistance phenotype of the epidemic strain. Biotyping (three biotypes), DNA plasmid analysis (four profiles) and ribotyping (two profiles) were poorly sensitive, in contrast to IS-typing (12 profiles). By the latter method, a coefficient of similarity (percentage similarity) compared to the predominant IS profile was calculated. Strains with a coefficient of similarity $\geqslant 82 \%$ were considered as highly related to the epidemic strain, while those with a coefficient of similarity $\leqslant 40 \%$ were regarded as distant. Results obtained with the five markers confirmed that an outbreak of hospital infection had occurred in the plastic surgery ward, with spread of the epidemic strain throughout the hospital.
\end{abstract}

\section{Introduction}

Methicillin-resistant Staphylococcus aureus (MRSA) is an opportunist pathogen that causes frequent outbreaks of infection in hospitals. MRSA strains are phenotypically similar and appear to belong to an evolutionarily restricted subpopulation of $S$. aureus [1]. Most MRSA strains worldwide have gradually become resistant to additional antibiotics, such as aminoglycosides, macrolides, lincosamides, tetracyclines and, more recently, fluoroquinolones [2,3]. As a result, discrimination between endemic and epidemic situations by antibiotyping is often difficult. At present, resistance to lincosamides and to factor $\mathrm{A}$ of streptogramin $\left(\mathrm{LS}_{A}\right.$ phenotype) is uncommon among MRSA isolates and although the mechanism of resistance is uncompletely understood, it appears to be chromosomally mediated [4]. A significant increase in isolates of this kind in the Pellegrin Hospital, Bordeaux, France, especially in a plastic surgery ward, strongly suggested an outbreak of hospital infection.

Epidemiological investigations of MRSA have been

Received 30 May 1995; revised version accepted 31 July 1995.

Corresponding author: Dr C. Arpin. based on non-molecular markers such as antibiotyping [5], lysotyping [6] and serotyping [7]. The two latter techniques are subject to considerable variations, are labour intensive, have limited availability, lack standardisation and are generally limited to reference laboratories. The development of DNA-based techniques has provided clinical laboratories with the means to characterise isolates at the molecular level $[8,9]$.

The value of antibiotyping, biotyping and three molecular methods (plasmid profile, ribotyping and insertion sequence [IS] typing with an IS256 sequence as a probe) were examined in the investigation of a presumed outbreak of hospital infection.

\section{Materials and methods}

\section{Epidemiological investigation and MRSA strains}

The Pellegrin Hospital, Bordeaux, is a 1500-bed university-affiliated hospital, including mainly surgical (c. 950 beds) and intensive care (c. 200 beds) units. Between May 1991 and May 1992, 38 isolates of MRSA that were also resistant to lincomycin, clindamycin and pristinamycin IIA, were obtained from 27 patients. Of these isolates, 28 were from wound 
samples of 17 patients in a plastic surgery unit. This unit is in a separate building and is composed of a 26bed ward, a four-bed day care unit, a consulting office, an operating theatre suite and a recovery room (three intensive care beds).

For the study, isolates were divided into three groups: 17 isolates with the LS $_{A}$-MRSA phenotype from patients in the suspected outbreak ward (group I; only the first isolate from each patient was studied); 16 isolates of MRSA from other units of the hospital during the same period, including 10 isolates with the $\mathrm{LS}_{A}$ phenotype, and six random isolates of MRSA without this phenotype (group II); four strains (group III) obtained from one patient in the plastic surgery unit over an 18-month period.

$S$. aureus isolates were identified by a tube test for free coagulase and a slide test for clumping factor. They were cultivated in Brian Heart Infusion (BHI; Difco) Broth and Agar.

\section{Escherichia coli strains and plasmids}

Two Escherichia coli strains were used. E. coli $\mathrm{HB} 101$ harboured plasmid pKK3535, a pBR322 derivative plasmid containing the $r r n \mathrm{~B}$ ribosomal operon of $E$. coli $[10]$. E. coli TG1 contained plasmid pISM1001 (a gift of F. C. Minion) which consists of an E. coli pKS plasmid carrying $S$. aureus $\operatorname{Tn} 4001$ [11]. Tn 4001 is a small $(4.7 \mathrm{~kb})$ composite class I transposable element which encodes the bifunctional enzyme AAC (6 $\left.6^{\prime}\right)$ $\mathrm{APH}\left(2^{\prime \prime}\right)$ specifying kanamycin-gentamicin-tobramycin resistance and which is flanked by the $1.3-\mathrm{kb}$ insertion element IS256 [12].

The E. coli strains were grown in Luria Broth (LB, GibcoBRL) at $37^{\circ} \mathrm{C}$ with aeration.

\section{Antibiotic susceptibility testing}

Susceptibility to 32 antimicrobial agents was determined by a standard disk diffusion method [13]. Commercially available disks (Diagnostic Pasteur) loaded with the following antibiotics were used: penicillin G $6 \mu \mathrm{g}$, oxacillin $5 \mu \mathrm{g}$, streptomycin $10 \mathrm{I} . \mathrm{U}$., spectinomycin $100 \mu \mathrm{g}$, kanamycin $30 \mathrm{I} . \mathrm{U}$. , neomycin $30 \mathrm{I} . \mathrm{U}$., gentamicin $15 \mu \mathrm{g}$, netilmicin $30 \mu \mathrm{g}$, tobramycin $10 \mu \mathrm{g}$, amikacin $30 \mu \mathrm{g}$, erythromycin 15 I.U., spiramycin $100 \mu \mathrm{g}$, lincomycin $15 \mu \mathrm{g}$, clindamycin 2 I.U., pristinamycin $15 \mu \mathrm{g}$, ofloxacin $5 \mu \mathrm{g}$, tetracycline 30 I.U., minocycline 30 I.U., sulphonamides $200 \mu$ g, trimethoprim $5 \mu \mathrm{g}$, co-trimoxazole (trimethoprim:sulphonamides, 1.25: $23.75 \mu \mathrm{g}$ ), fosfomycin $50 \mu \mathrm{g}$, vancomycin $30 \mu \mathrm{g}$, teicoplanin $30 \mu \mathrm{g}$, fusidic acid $10 \mu \mathrm{g}$, rifampicin $30 \mu \mathrm{g}$, chloramphenicol $30 \mu \mathrm{g}$, bacitracin $130 \mu \mathrm{g}$, nitrofurantoin $300 \mu \mathrm{g}$ and nitroxoline $20 \mu \mathrm{g}$. Additional disks containing either $20 \mu \mathrm{g}$ of pristinamycin IIA or $40 \mu \mathrm{g}$ of pristinamycin IB were prepared in our laboratory.

\section{Biotyping}

The $S$. aureus isolates were biotyped with the API Staph system (bioMérieux) according to the manufacturer's recommendations.

\section{Plasmid and chromosomal DNA isolation and analysis}

Plasmid DNA from E. coli was isolated and purified by caesium chloride-ethidium bromide gradient centrifugation [14]. Plasmid DNA from MRSA strains was extracted by a modification of the Birnboim and Doly procedure [15] in which lysostaphin (Sigma), $1 \mathrm{mg} / \mathrm{ml}$, was substituted for lysozyme. Total cellular DNA of MRSA isolates was purified as described previously [16]. DNA samples were digested with the restriction endonucleases EcoRI and HindIII as recommended by the manufacturer (GibcoBRL). Electrophoresis of plasmid and total digested DNA was performed on agarose $(0.8 \% \mathrm{w} / \mathrm{v}$ gels $)$ in Tris-borate or Tris-acetate buffer ( $\mathrm{pH}$ 8.3) as described by Sambrook et al. [14]. The $\lambda$ DNA phage digested by PstI or HindIII was used as a size marker.

\section{Blotting and hybridisation}

DNA was transferred from agarose gels to Hybond-N nylon filters (Schleicher and Schuell) by a vacuum blotting system (Appligene). The blotted DNA was fixed by UV irradiation at $305 \mathrm{~nm}$ for $5 \mathrm{~min}$. Purified plasmid DNA (pKK3535 and pISM1001) was labelled with $\left[\alpha^{32} \mathrm{P}\right] \mathrm{dCTP}(110 \mathrm{TBq} / \mathrm{mmol}$; Dupont NEN Research products) by the nick-translation labelling system (Amersham International) according to the manufacturer's instructions. The pre-hybridisation, hybridisation and washing steps were performed under stringent conditions as described previously [17]. The blots were exposed to Fuji RX films at $-70^{\circ} \mathrm{C}$ with intensifying screens for various lengths of time.

\section{Comparison of hybridisation patterns}

The percentage similarity between pairs of hybridisation patterns was calculated from the formula [18]:

$$
\% \mathrm{~S}=\frac{\mathrm{N} \times 2}{\mathrm{~T}} \times 100
$$

where $\mathrm{N}$ is the number of matching bands and $\mathrm{T}$ is the total number of bands. A dendrogram was constructed by computer by the unweighted pair group method with averages.

\section{Results}

\section{Epidemiological data}

The age of the 17 patients in the plastic surgery unit ranged from 20 to 64 years (mean, 37 years). Thirteen were male and four were female. The temporal 


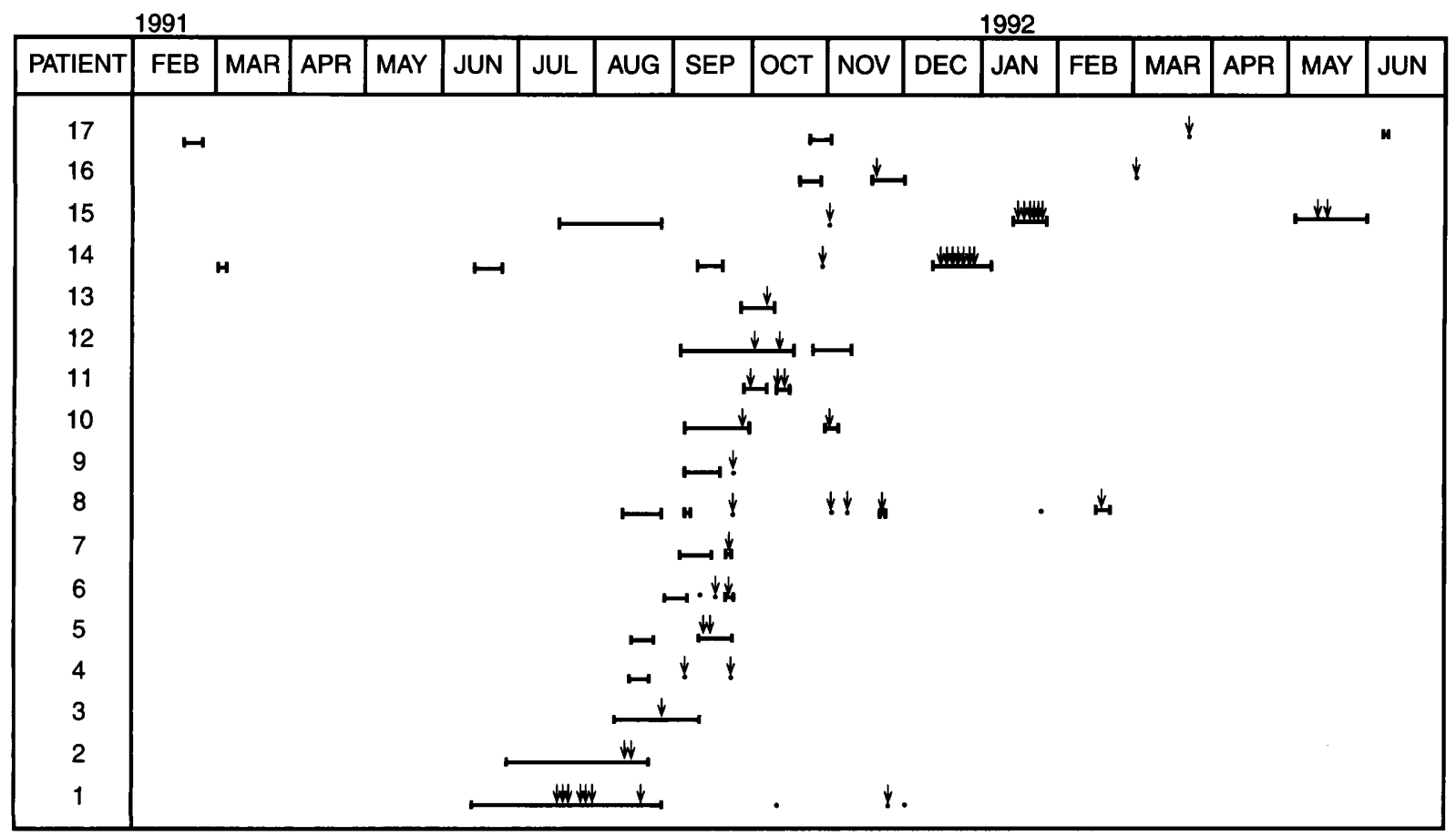

Fig 1. Temporal relationship between the 17 patients with LS $_{A}$-MRSA strains in the plastic surgery ward. Symbols: $\mapsto$ period during which patient was in hospital; $\downarrow$ isolation of an $\operatorname{LS}_{A}$-MRSA strain.

relationship between the patients of this ward shows the presence of at least one infected patient during the epidemic peak, i.e., from June 1991 to January 1992 (Fig. 1). The patients carrying isolates assigned to group II were geographically distant from the plastic surgery ward and no epidemiological link could be demonstrated between them.

\section{Antibiotic susceptibility testing}

All MRSA isolates were resistant to penicillin $G$ and oxacillin. The phenotype of resistance to aminoglycosides was presumptively due to the production of at least two modifying enzymes including $\mathrm{AAC}\left(6^{\prime}\right)$ $\operatorname{APH}\left(2^{\prime \prime}\right)$ [19]. All isolates were resistant to tetracyclines, quinolones and fosfomycin. Three phenotypes of resistance to macrolides-lincosamides and streptogramins were observed: resistance to lincomycin and pristinamycin IIA, and resistance to macrolides and pristinamycin IB either constitutively or inducibly expressed [20]. In addition, six isolates of group II were resistant to spectinomycin and co-trimoxazole; among them, one was also resistant to chloramphenicol. High or low level of rifampicin resistance was another characteristic. Accordingly, five antibiotypes (A1-A5) were defined (Table 1). All isolates of group I and 10 isolates of group II (strains with the LS $_{A}$ phenotype) exhibited the same antibiotype. The six other isolates of group II displayed four different patterns of susceptibility.

\section{Biotyping}

All isolates were identified by the API system as $S$. aureus. Three biotypes were recognised: those that produced arginine dihydrolase but not nitrate reductase; those that produced nitrate reductase but not arginine dihydrolase; and those that produced both. All isolates of group I and 10 isolates of group II with the $\mathrm{LS}_{A}$ phenotype belonged to the first biotype (B1). The six other isolates of group II were of two remaining biotypes (Table 1).

\section{Plasmid profile}

No plasmid was found in the isolates with the $\mathrm{LS}_{A}$ phenotype despite repeated attempts. In contrast, the six isolates of group II that did not exhibit the $\mathrm{LS}_{A}$ phenotype showed three distinct plasmid profiles. The approximate sizes of the bands of unrestricted plasmids are indicated in Table 2 and the distribution of these profiles among the isolates is shown in Table 1. For the four isolates with the antibiotic patterns designated A2 and A4, plasmid profiles P1 (four bands) and P3 (five bands) were observed. The two isolates with the antibiotypes $\mathrm{A} 3$ and $\mathrm{A} 5$ both showed plasmid profile P2 (two bands).

\section{Hybridisation patterns obtained with probe pKK3535 (ribotyping)}

With plasmid pKK3535 as probe, only two hybridisation patterns were obtained when the DNA of group I and II strains was digested with HindIII. No hybridisation was observed when the same DNA was probed with plasmid pBR322 (data not shown). The hybridisation patterns designated $\mathrm{H} 1$ (eight bands) and $\mathrm{H} 2$ (nine bands) were reproducible (Fig. 2); they differed only by 


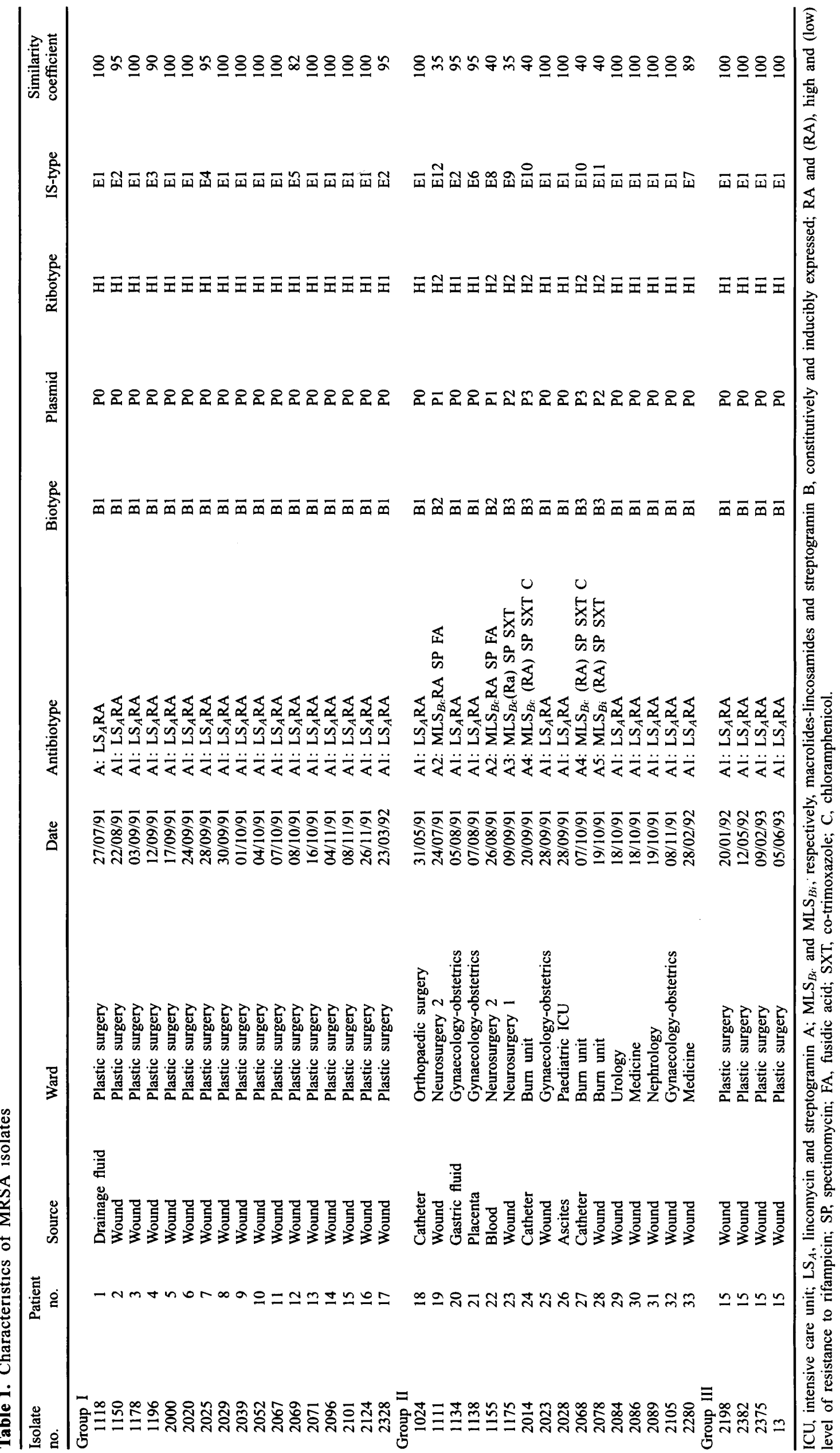


Table 2. Analysis of DNA plasmid patterns of MRSA

\begin{tabular}{ll}
\hline Plasmid pattern & Size of DNA bands* $(\mathrm{kb})$ \\
\hline P0 & No plasmid \\
P1 & $30,35,2.8,2.5$ \\
P2 & 30,35 \\
P3 & $5.5,2.9,2.6,1.3,1.1$ \\
\hline
\end{tabular}

*Bands of unrestricted plasmids.

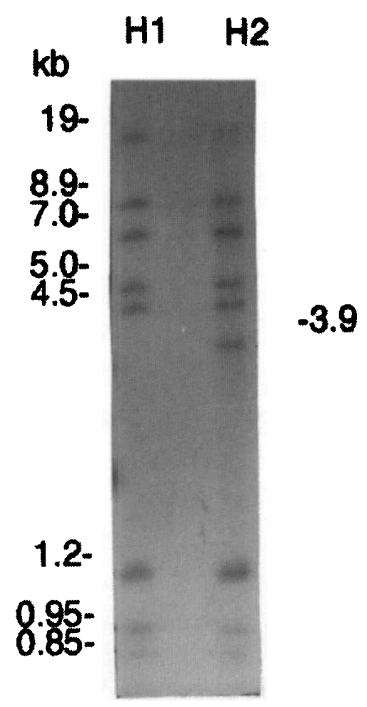

Fig. 2. Profiles $\mathrm{H} 1$ and $\mathrm{H} 2$ obtained by Southern blot analysis of HindIII-digested total DNA detected in the 32 MRSA strains with the $\alpha^{32} \mathrm{P}$-labelled pKK3535 plasmid as a probe. Numbers indicate the sizes of DNA fragments obtained in $\mathrm{kb}$. a single band of c. $3.9 \mathrm{~kb}$ which was present in the profile H2. All 17 isolates of group I and group II isolates with the $\mathrm{LS}_{A}$ phenotype gave the profile $\mathrm{H} 1$. The six other isolates of group II gave the profile $\mathrm{H} 2$ (Table 1).

\section{Hybridisation patterns obtained with probe pISM1001 (IS-typing)}

The DNA of the 33 isolates of groups I and II hybridised with the pISM1001 probe but not with the plasmid pKS which lacks the Tn 4001 transposon (data not shown). Twelve different patterns consisting of 916 fragments were observed when the DNA was hydrolysed by EcoRI (profiles E) (Fig. 3A and B). At least two unrelated hybridisation experiments were done to ensure that these patterns were reproducible. Among group I isolates, five profiles were obtained (E1-E5). In group II, nine hybridisation patterns were found (E1, E2, E6-E12). Profile E1 was predominant in the two groups. The distribution of the $\mathrm{E}$ profiles and their percentage similarity $(\% \mathrm{~S})$ based on the Dice index [18] was calculated for each MRSA isolate and compared with the profile E1 (Table 1). These percentages varied from 82 to $100 \%$ for $\mathrm{LS}_{A}$-MRSA isolates and 35 to $40 \%$ for non-LS $A_{A}$-MRSA isolates. Furthermore, when the overall similarity was calculated between each pair of MRSA isolates, the values ranged from 17 to $100 \%$. The corresponding dendrogram shows that the isolates were divided in two groups (Fig. 4): the $\mathrm{LS}_{A}$-resistant strains that exhibited a hybridisation pattern either identical to or highly related to E1, and the six remaining strains of group II with a very

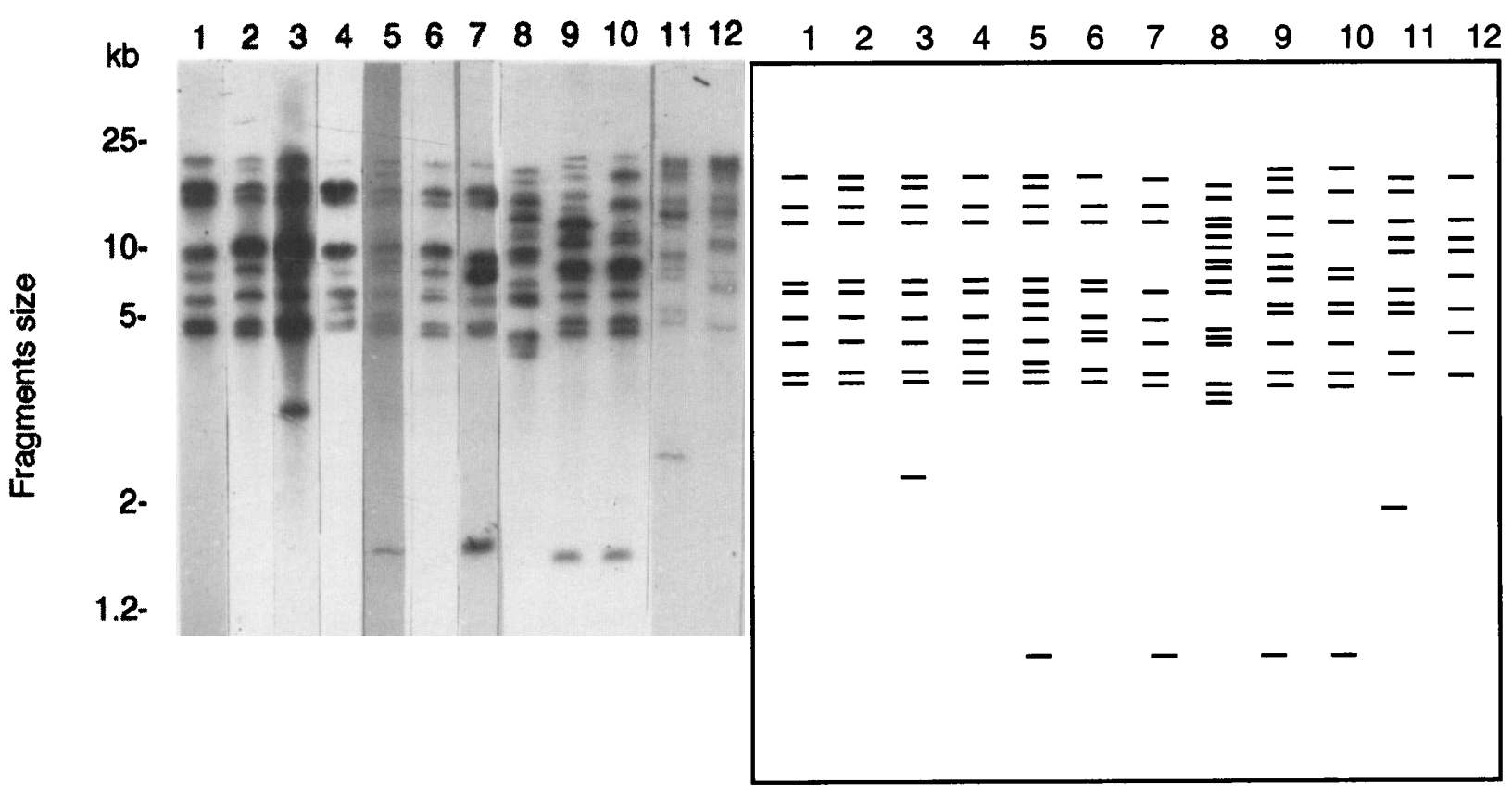

Fig. 3. Profiles obtained by a, Southern blot analysis of EcoRI-digested total DNA detected in the 32 MRSA strains with the $\alpha^{32} \mathrm{P}$-labelled pISM1001 plasmid as a probe; b, schematic representation. Lanes 1-12 correspond respectively to profiles E1-E12. 
Percentage similarity

$\begin{array}{lllllllllll}0 & 10 & 20 & 30 & 40 & 50 & 60 & 70 & 80 & 90 & 100\end{array}$

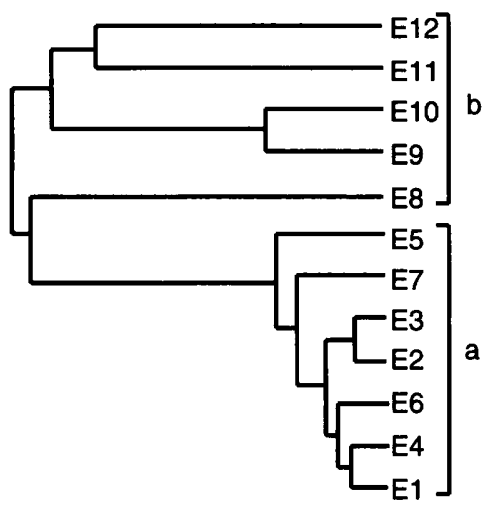

Fig. 4. Dendrogram of percentage similarity based on computer-assisted comparison of DNA fingerprints obtained by the IS-type method for a, $\mathrm{LS}_{A}$-MRSA and b, non-LS ${ }_{A}$-MRSA strains.

different pattern. In the latter group, two strains respectively with the profiles E8 (1155) and E12 (1111) exhibited a highly different hybridisation pattern (coefficient of similarity: 17\%) but were identical by their antibiotype (A2), biotype (B2), plasmid profile (P1) and ribotype (H2).

\section{Genetic stability of Tn4001}

The high degree of restriction fragment length polymorphism obtained with the pISM1001 probe indicated that the Tn 4001 transposon and the IS256 element, or both, were present in numerous copies in the chromosomal DNA of the MRSA isolates studied. To investigate the frequency of genetic re-arrangement in the DNA, four isolates collected from the same patient during a 1.5-year period were analysed (strains of group III, Table 1). No change in the profile E1 was observed (data not shown). The same result was obtained with two isolates from another patient belonging to group II. Moreover, one isolate (2101, group I) was subcultivated 20 times without any change in its E1 profile (data not shown).

\section{Discussion}

The $17 \mathrm{LS}_{A}$-MRSA isolates from the plastic surgery unit were found to be identical or very similar by all five epidemiological markers, suggesting transmission of a single strain responsible for an outbreak of hospital infection. The primary means of cross-transmission of MRSA is on the hands of colonised staff [21], and this is likely to be the principal source of transmission, as most of the newly infected cases had an overlapping stay in the ward. Moreover, the simple re-inforcement of conventional hygiene measures was sufficient to control the epidemic situation. The 10 isolates of the control group II gave the same results with the epidemiological typing methods used. This suggests the spread of the epidemic strain throughout the hospital, without direct transfer, as reported for other MRSA outbreaks [22]. The six isolates of group II that lacked the $\mathrm{LS}_{A}$ phenotype were completely different by all markers.

Among conventional typing methods, the antimicrobial susceptibility profile is attractive as it is readily available, easy to perform and relatively inexpensive. However, it has limited sensitivity for organisms such as MRSA which are often multiresistant. Also, the antibiotic susceptibility pattern may be unstable owing to the selective pressure in the hospital. In the present study, antibiotyping worked very well because the epidemic strain harboured an uncommon antibiotic resistance phenotype. The presence of strains carrying an unusual combination of drug resistances is a good indication of the dissemination of an epidemic strain, but additional typing methods are required for a proper epidemiological assessment.

Biotyping is also simple to perform when commercial kits are available, as for staphylococci. However, these systems are designed for taxonomic rather than epidemiological purposes and often lack sensitivity, particularly for $S$. aureus. Furthermore, the biotype may be influenced by various technical and environmental factors [23, 24]. In this study, only three distinct biotypes were found (Table 1) but these results correlated well with the other markers.

Plasmid DNA analysis has been usefully applied in a number of epidemiological studies [5, 9, 23, 24], but the profile is markedly influenced by the plasmid extraction procedure, which may convert one molecular form of the plasmid to another. The discriminatory power of this method increases with the number of plasmids and the differences in their molecular sizes; strains may lose or acquire antibiotic resistance or cryptic plasmids, and existing plasmids can undergo molecular re-arrangements. Several reports indicate that MRSA isolates often carry few, if any, plasmids [25] perhaps related to the chromosomal location of resistance determinants in MRSA [26]. The study strains exhibited four plasmid profiles, but no plasmid was detected in the $\mathrm{LS}_{A}$ isolates, so that this method was undiscriminatory.

Ribotyping has been proposed as a useful molecular marker for MRSA [27]. However, in general, MRSA typing with a rDNA probe shows relative genetic homogeneity, reinforcing the hypothesis that many MRSA isolates may have evolved recently from a single ancestral strain $[1,28]$. In the present study, the two profiles that were found shared a high degree of homology, although isolates with the non- $\mathrm{LS}_{A}$ phenotype were very different by other markers. Ribotyping did not adequately discriminate among the MRSA isolates examined. 
Plasmids containing the genetic mobile element IS256 can be used as an epidemiological tool for typing gentamicin-resistant staphylococci with a good discriminatory power [28-30]. With a similar probe, 12 different hybridisation patterns were obtained. Among the $\mathrm{LS}_{A}$ strains, profile E1 was predominant (17 of 28 strains) and the six remaining patterns were very similar to E1. The six non-LS $A$ strains gave five hybridisation patterns that were very different from E1. As an IS element has inherently the potential to cause genetic re-arrangements [31], the stability of this marker was tested. No change in the profile of a strain was observed after a 1.5-year period in the same patient and of another strain after 20 in-vitro subcultures. These results demonstrate that under the conditions of this study, the mobile element IS256 is relatively stable during a considerable number of invitro and in-vivo generations. These results are in agreement with those of Dyke et al. [32] who found no evidence for mobility of IS256 after a total of 126 generations. However, considering that IS256 is able to transpose at different sites of the chromosomal DNA, strains with a similarity coefficient $\geqslant 82 \%$ were regarded as related to the epidemic strain, and those with a coefficient $\leqslant 40 \%$ as unrelated.

In a recent study [33], the strengths and weaknesses of 12 currently available typing systems were assessed for their ability to discriminate among MRSA and methicillin-susceptible $S$. aureus. No typing method prevailed clearly among others. Insertion sequence typing, with IS275/431 sequences as probes, was relatively effective with MRSA strains, but ineffective with methicillin-sensitive isolates which rarely carry these sequences [34]. In other studies, pulsed-field gel electrophoresis appears as the 'gold standard' test for typing $S$. aureus strains [35], even when compared to the arbitrarily primed PCR [36]. Ultimately, a combination of two methods might be most efficacious, the choice depending on the resources of each laboratory and the level of expertise of the personnel in particular techniques.

\section{References}

1. Lacey RW, Grinsted J. Genetic analysis of methicillin-resistant strains of Staphylococcus aureus: evidence for their evolution from a single clone. $J$ Med Microbiol 1973; 6: 511-526.

2. Acar JF, Buu-Hoï AY. Resistance patterns of important Grampositive pathogens. J Antimicrob Chemother 1988; 21 Suppl C: 41-47.

3. Maple PAC, Hamilton-Miller JMT, Brumfitt W. World-wide antibiotic resistance in methicillin-resistant Staphylococcus aureus. Lancet 1989; 1: 537-540.

4. Leclercq R, Courvalin P. Intrinsic and unusual resistance to macrolide, lincosamide, and streptogramin antibiotics in bacteria. Antimicrob Agents Chemother 1991; 35: 1273-1276.

5. Archer GL, Mayhall CG. Comparison of epidemiological markers used in the investigation of an outbreak of methicillin-resistant Staphylococcus aureus infections. J Clin Microbiol 1983; 18: 395-399.

6. Blair JE, Williams REO. Phage typing of staphylococci. Bull
WHO 1961; 24: 771-784.

7. Chabbert YA, Pillet J. Correlation between 'methicillin resistance' and serotype in Staphylococcus. Nature 1967; 213: 1137

8. Goering RV, Duensing TD. Rapid field inversion gel electrophoresis in combination with an rRNA gene probe in the epidemiological evaluation of staphylococci. J Clin Microbiol 1990; 28: 426-429.

9. Zuccarelli AJ, Roy I, Harding GP, Couperus JJ. Diversity and stability of restriction enzyme profiles of plasmid DNA from methicillin-resistant Staphylococcus aureus. J Clin Microbiol 1990; 28: 97-102.

10. Brosius J, Ullrich A, Raker MA et al. Construction and fine mapping of recombinant plasmids containing the $r r n \mathrm{~B}$ ribosomal RNA operon of E. coli. Plasmid 1981; 6: 112-118.

11. Mahairas GG, Minion FC. Transformation of Mycoplasma pulmonis: demonstration of homologous recombination, introduction of cloned genes, and preliminary description of an integrating shuttle system. $J$ Bacteriol 1989; 171: 1775-1780.

12. Lyon BR, May JW, Skurray RA. Tn4001: a gentamicin and kanamycin resistance transposon in Staphylococcus aureus. Mol Gen Genet 1984; 193: 554-556.

13. Courvalin P, Goldstein F, Philippon A. Sirot J (eds). L'antibiogramme. Paris, Vigot. 1985.

14. Sambrook J, Fritsch EF, Maniatis T (eds). Molecular cloning: a laboratory manual 2nd edn. Cold Spring Harbor Laboratory Press, Cold Spring Harbor, NY. 1989.

15. Birnboim HC, Doly J. A rapid alkaline extraction procedure for screening recombinant plasmid DNA. Nucleic Acids Res 1979; 7: 1513-1523.

16. De Buyser ML, Morvan A, Grimont F, El Solh N. Characterization of Staphylococcus species by ribosomal RNA gene restriction patterns. $J$ Gen Microbiol 1989; 135 : 989-999.

17. Grimont F, Grimont PAD. Ribosomal ribonucleic acid gene restriction patterns as potential taxonomic tools. Ann Inst Pasteur Microbiol 1986; 137B: 165-175.

18. Dice LR. Measures of the amount of ecologic association between species. Ecology 1945; 26: 297-302.

19. Bismuth $\mathrm{R}$. Cocci à Gram positif et aminosides. In: Courvalin PF, Goldstein A, Philippon, Sirot J (eds) L'Antibiogramme, Paris, Vigot. 1985: 29-39.

20. Leclercq $R$, Courvalin $P$. Bacterial resistance to macrolide, lincosamide, and streptogramin antibiotics by target modification. Antimicrob Agents Chemother 1991; 35: 12671272.

21. Boyce JM. Should we vigorously try to contain and control methicillin-resistant Staphylococcus aureus? Infect Control Hosp Epidemiol 1991; 12: 46-53.

22. Collins JK, Smith JS, Kelly MT. Comparison of phage typing, plasmid mapping and antibiotic resistance patterns as epidemiologic markers in a nosocomial outbreak of methicillinresistant Staphylococcus aureus infections. Diagn Microbiol Infect Dis 1984; 2: 233-245.

23. Mulligan ME, Arbeit RD. Epidemiologic and clinical utility of typing systems for differentiating among strains of methicillinresistant Staphylococcus aureus. Infect Control Hosp Epidemiol 1991; 12: 20-28.

24. Pfaller MA. Typing methods for epidemiologic investigation In: Balows A, Hausler WJ, Herrmann $\mathrm{KL}$, Isenberg $\mathrm{HD}$, Shadomy HJ (eds) Manual of clinical microbiology, 5th edn Washington, DC, American Society for Microbiology. 1991: 171-182.

25. Cristino JA, Pereira AT. Plasmid analysis of 219 methicillinresistant Staphylococcus aureus strains with uncommon profiles isolated in Lisbon. J Hosp Infect 1989; 13: 133-141.

26. Kayser FH, Berger-Bächi B, Beck WD. Genetics of multiplyresistant Staphylococcus aureus. J Hosp Infect 1986; 7 Suppl A: $19-27$.

27. Blumberg HM, Rimland D, Kiehlbauch JA, Terry PM, Wachsmuth IK. Epidemiologic typing of Staphylococcus aureus by DNA restriction fragment length polymorphisms of rRNA genes: elucidation of the clonal nature of a group of bacteriophage-nontypeable, ciprofloxacin-resistant, methicillinsusceptible $S$. aureus isolates. J Clin Microbiol 1992; 30: 362369.

28. Monzon-Moreno C, Aubert S, Morvan A, El Solh N Usefulness of three probes in typing isolates of methicillinresistant Staphylococcus aureus (MRSA). J Med Microbiol 
1991; 35: 80-88.

29. Walcher-Salesse S, Monzon-Moreno C, Aubert S, El Solh N. An epidemiological assessment of coagulase-negative staphylococci from an intensive care unit. J Med Microbiol 1992; 36: 321-331.

30. Loncle V, Casetta A, Buu-Hoi A, El Solh N. Analysis of pristinamycin-resistant Staphylococcus epidermidis isolates responsible for an outbreak in a Parisian Hospital. Antimicrob Agents Chemother 1993; 37: 2159-2165.

31. Galas DJ, Chandler M. Bacterial insertion elements. In: Berg DE, Howe MM (eds) Mobile DNA. Washington, DC, American Society for Microbiology. 1989: 109-162.

32. Dyke KGH, Aubert S, El Solh N. Multiple copies of IS256 in staphylococci. Plasmid 1992; 28: 235-246.

33. Tenover FC, Arbeit R, Archer G et al. Comparison of traditional and molecular methods for typing isolates of Staphylococcus aureus. J Clin Microbiol 1994; 32: 407-415.

34. Kreiswirth B, Kornblum J, Arbeit RD et al. Evidence for a clonal origin of methicillin resistance in Staphylococcus aureus. Science 1993; 259: 227-230.

35. Struelens MJ, Deplano A, Godard C, Maes N, Serruys E. Epidemiologic typing and delineation of genetic relatedness of methicillin-resistant Staphylococcus aureus by macrorestriction analysis of genomic DNA by using pulsed-field gel electrophoresis. J Clin Microbiol 1992; 30: 2599-2605.

36. Saulnier P, Bourneix C, Prévost G, Andremont A. Random amplified polymorphic DNA assay is less discriminant than pulsed-field gel electrophoresis for typing strains of methicillin-resistant Staphylococcus aureus. J Clin Microbiol 1993; 31: 982-985. 